\title{
Bite envenomation by Latrodectus geometricus (Araneae: Theridiidae) spiders in Malaysia
}

\author{
Mokhtar, A.S. ${ }^{1}$, Muslimin, M. ${ }^{2}$, Mat-Saat, A.Y. ${ }^{2}$, Ghazali, A-R.M. ${ }^{3}$, Ismail, A.K. ${ }^{4}$, Abdul-Aziz, N.M. ${ }^{3}$ \\ ${ }^{1}$ Department of Microbiology, Faculty of Medicine, Manipal University College Malaysia, Jalan Batu Hampar, 75150 Bukit Baru, Melaka, Malaysia \\ ${ }^{2}$ Department of Medical Science \& Technology, Faculty of Health Sciences, PICOMS International University College, 50400 Kuala Lumpur, Malaysia \\ ${ }^{3}$ Invertebrate \& Vertebrate Neurobiology Laboratory, Department of Parasitology, Faculty of Medicine, Universiti Malaya, 50603 Kuala Lumpur, Malaysia \\ ${ }^{4}$ Department of Emergency Medicine, Faculty of Medicine, Universiti Kebangsaan Malaysia, 56000 Kuala Lumpur, Malaysia \\ *Corresponding author: noisha@ummc.edu.my (Noraishah Mydin Abdul Aziz); khaldun_ismail@yahoo.com (Ahmad Khaldun Ismail)
}

\section{ARTICLE HISTORY}

Received: 5 October 2021

Revised: 24 November 2021

Accepted: 24 November 2021

Published: 31 December 2021

\begin{abstract}
We report two confirmed human bite cases by Lactrodectus geometricus, also known as the brown widow spider. These are the first reported bite envenomation incidents by L. geometricus in Malaysia. The incidents occurred in Tawau, Sabah and Paka, Terengganu. Both men were bitten on their ear while putting on motorcycle helmets. The spiders appeared to have nested in the helmets. The dead specimens were collected and sent to the Invertebrate and Vertebrate Neurobiology Laboratory, Department of Parasitology, Universiti Malaya for identification. The species identity was confirmed by DNA barcoding.
\end{abstract}

Keywords: Envenomation; Lactrodectus geometricus; DNA barcoding; Malaysia; anxiety due to Covid-19.

\section{INTRODUCTION}

The brown widow spider, Latrodectus geometricus (Koch, 1841) is one of thirty-two recognized Lactrodectus species (World Spider Catalog, 2021). Thought to be native to southern Africa, L. geometricus has gradually expanded its range to cover both temperate and tropical ecosystems globally (Taucare-Ríos et al., 2016). The species is commonly seen in residential areas due to its affinity for building structures (Jiménez, 1998; Muslimin et al., 2015; Rocha et al., 2017).

Morphologically, L. geometricus is identifiable by its four pairs of eyes positioned in two parallel rows, a comb-feet arranged in a comb-like row bristles on the tarsi of the hind legs, and distinctive paired spermathecae with coiled copulatory ducts (Muslimin et al., 2015). Its legs differ in length; with few spines on the tibiae and metatarsi, and the tarsus tapers towards the tip of its leg (Koh \& Leong, 2013). It also has a yellow-orange or red-orange hourglass-shaped marking on the ventral abdomen, rather than bright red of the black widows (Koh \& Leong, 2013; Earwood et al., 2020). In addition, L. geometricus is the only known spider egg sacs with spherical-spikey shape (de Luna et al., 2020).

The brown widow spider is known to be non-aggressive and only bites when threatened (Muslimin et al., 2015). It also exhibits thanatosis, a behaviour characterized by jumping from its web, retracting its legs and playing dead when its protective retreat is disturbed (Vetter, 2008). Being the renowned relative of the notorious American black widow, Lactrodectus mactans, the brown widow bite envenomation effect is generally considered mild but it may potentially lead to severe envenomation similar to black widow bites, including severe pain, cramps, nausea and vomiting (Goddard et al., 2008). Despite its broad distribution worldwide, incidents of $L$. geometricus bite are poorly documented, and to date, medical literature of L. geometricus envenoming in Malaysia is non-existent.

\section{Case report 1}

A 36-year-old man in Tawau, Sabah $\left(4^{\circ} 18^{\prime} 32.0^{\prime \prime} \mathrm{N}, 118\right.$ $\left.{ }^{\circ} 01^{\prime} 06.0 " \mathrm{E}\right)$, was bitten by a brown coloured spider on his right ear while wearing a motorcycle helmet. He complained of immediate severe pain on his right ear and found the culprit spider in the helmet. The spider was killed by insecticide spray and kept in a specimen container (Figure 1A). He complained of severe pain of $9 / 10$ on the verbal numerical rating score (VNRS) mainly at the bite site with erythema and oedema over the pinna (Figure 1B). Within 15 minutes after the bite incident, his neck and back felt numb with a burning sensation at the bite site. He had difficulty in sleeping due to the pain. Despite reporting that the pain to be a constant in nature, he did not seek medical attention due to the worry of contracting Covid-19 from the hospital as the average of daily cases reported have risen and Tawau was in the red zone. However, he self-medicated with several courses of chlorpheniramine maleate and paracetamol tablets orally for a couple of days. He did not complain of any neurological signs or symptoms nor pyrexia. The pain and oedema gradually subsided by the third day. The 


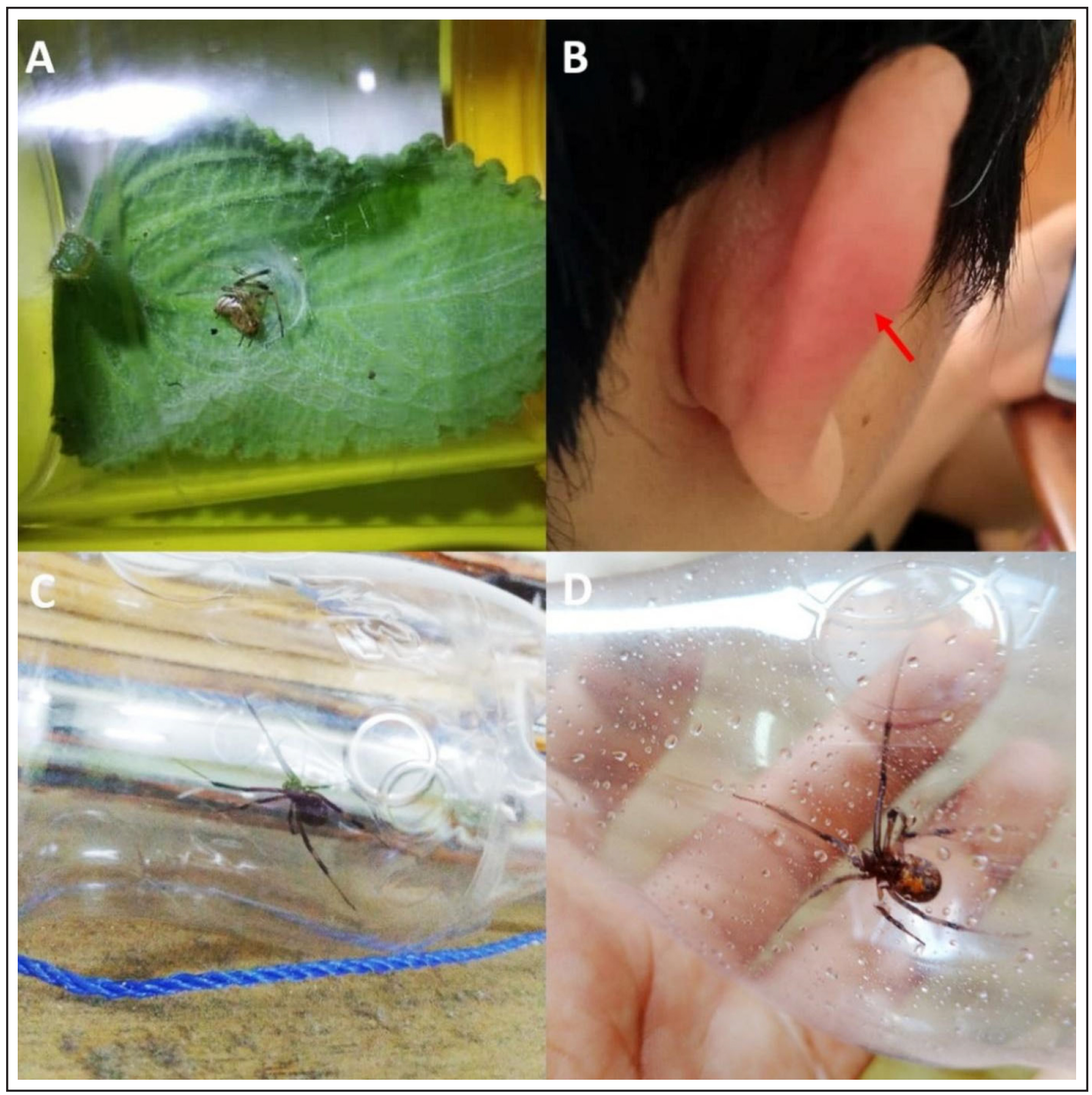

Figure 1. (A) Brown widow spider specimen from Tawau, Sabah. (B) Erythema and oedema of the pinna of the right ear. The puncture wound from the bite is marked by the red arrow. (C) and (D) Brown widow spider specimens from Paka, Terengganu.

specimen was then sent to the Invertebrate and Vertebrate Neurobiology Laboratory, Universiti Malaya in Kuala Lumpur for identification and analysis.

\section{Case report 2}

A 37 -year-old man in Paka, Terengganu $\left(4^{\circ} 36^{\prime} 58.892^{\prime \prime} \mathrm{N}\right.$, $\left.103^{\circ} 26^{\prime} 33.123^{\prime \prime E}\right)$, was bitten by brown coloured spiders upon wearing a motorcycle helmet. He felt a sudden pain on the left ear. Upon removing the helmet, he saw several tiny spiders scurrying inside the helmet. The patient did not kill the spiders but instead carefully placed them inside a plastic bottle (Figure 1C and 1D). He then contacted the Invertebrate and Vertebrate Neurobiology Laboratory, Universiti Malaya for assistance in identifying the spiders. He was not complaining of significant pain and did not wish to seek medical attention despite being advised to do so. However, the pain gradually worsened and he experienced intense pain of $8 / 10$ vNRS over the pinna. He eventually decided to seek medical attention and went to Dungun Hospital. Patient claimed he was treated with two shots of different medications (one shot each) but he could not recollect the types of injections given. He was discharged home after a 5-hour observation at the Emergency Department and was also prescribed with mefenamic acid $250 \mathrm{mg}$ capsules. There was no documentation of any neurological signs or symptoms nor pyrexia. The pain and oedema gradually resolved over a period of two days. The specimens were sent to the Invertebrate and Vertebrate Neurobiology Lab, Universiti Malaya in Kuala Lumpur for identification and analysis. 


\section{MATERIALS AND METHODS}

The patients provided written consent for this study. The spider specimens were couriered to the Invertebrate and Vertebrate Neurobiology Lab, Department of Parasitology, Faculty of Medicine, Universiti Malaya, Kuala Lumpur Malaysia, for identification and analysis. Each specimen was examined under a stereomicroscope (Leica Microsystems, Germany), which revealed the four pairs of eyes positioned in two parallel rows, hourglass-shaped ventral streak, and comb-like bristles and banded legs (Figure 2). These morphological features are consistent with L. geometricus, and both specimens were confirmed as female spiders due to the absence of enlarged pairs of pedipalps.

DNA barcoding (Ratnasingham \& Hebert, 2013) was employed to identify the species of the spider specimens. DNA were extracted from the spider legs using the GeneJET Genomic DNA purification kit (Thermo Fisher Scientific, Lithuania), following the procedures recommended by the manufacturer. The $648 \mathrm{bp}$ fragments of cytochrome c oxidase subunit 1 (COI) mitochondrial DNA (mtDNA) gene were amplified using the "Lep" primer combinations via polymerase chain reaction (PCR) (Wilson, 2012). Cycle sequencing were performed bi-directionally using the PCR primers. BOLD identification trees of the spiders were produced by a full database sequence identification request in the BOLD website (Ratnasingham \& Hebert, 2007).

We further mapped the L. geometricus sightings in Malaysia as reported previously (Muslimin et al., 2015) including the current envenoming of Tawau and Paka, respectively, using QGIS (Version 3.18.2-Zürich); a geographic information system application (Lacaze et al., 2018). The locations of the sightings were subsequently mapped (Figure 3).

\section{RESULTS AND DISCUSSION}

Although L. geometricus are easily identifiable by their distinctive morphological characteristics, DNA barcoding technique was adopted to confirm the species. In this study, the two DNA barcodes obtained were similar to each other, except for one nucleotide change. They were matched $100 \%$ to L. geometricus in the Barcode of Life Data System (BOLD) (Ratnasingham \& Hebert, 2007) with BIN ID: BOLD: AAK7751, and nested within other DNA barcodes of L. geometricus on BOLD identification trees (Figures 4 and 5).

The Invertebrate and Vertebrate Neurobiology Laboratory, Department of Parasitology, Universiti Malaya is contacted periodically by concerned public reporting unusual spider sightings in and around their homes which interfere with their day-to-day activities. Often, spider specimens were sent to our lab for identification at the behest of the complainant.

L. geometricus sightings in Peninsular Malaysia were first reported beginning 2013 by Muslimin et al. (2015) supporting its far-reaching adaptability hence the observed global-wide invasion (Keyler et al., 2020). The two cases reported here further confirms the arrival of $L$. geometricus in East Malaysia. This also shows that the invasion of $L$. geometricus in Malaysia are particularly inclined to be adaptable to human habitation.

Known to colonize urban areas, L. geometricus is usually found living in clutter surrounding homes such as garages, woodpiles and gardening equipment (Vetter \& Isbister, 2008).
The spiders are believed to invade via transportation or trading systems, including human transport by air, land and sea; in which they were widely reported in transportation hubs or ports (Muslimin et al., 2015; Taucare-Ríos et al., 2016). In the Sabah case, the offending spiders were found in the motorcycle helmet that was left near flowerpots over a month. Whereas in the Terengganu case, the aetiology of the L. geometricus originated from a helmet too but one which travelled unperturbed in a car from the West Coast of Peninsular Malaysia to the East Coast of Peninsular Malaysia. When the owner of the helmet had retrieved the helmet from the car, he was subsequently bitten when he put on his helmet.

L. geometricus is considered to be non-aggressive because when threatened, they will withdraw from their webs and exhibit prolonged thanatosis (Mullen \& Durden, 2002; Goddard et al., 2008). However, lactrodectism due to L. geometricus, some with severe reactions, have been reported (Cardoso et al., 2003; Goddard et al., 2008; Almeida et al., 2009; Earwood et al., 2020). Despite the low average yield of venom produced by L. geometricus when compared against the other five Lactrodectus spp. studied in the United States (McCrone, 1964; Khamtorn et al., 2020), the brown widow spider produces similar venom composition to that of the black widow L. mactans (Garb \& Hayashi, 2013). The venom contains alpha-latrotoxin homolog, a potent vertebratespecific neurotoxin that acts in vertebrates via both the presence and absence of calcium ions, triggering a massive uncontrolled exocytosis of neurotransmitters (Garb \& Hayashi, 2013).

Health hazards from the brown widow spider have previously been considered insignificant. L. geometricus bites and envenomation usually cause local symptoms and tend to be localized to the bite site and its surrounding tissue (Almeida et al., 2009). However, severe reactions requiring hospitalization, even though rare, has been reported where the patient suffered from debilitating pain, cramps, vomiting, local burning and fasciculations (Goddard et al., 2008). Treatment for widow spider bites, including brown widow, is based on the severity of the symptoms. Oral analgesics such as oxycodone/acetominophen or ibuprofen can be prescribed to alleviate the pain (Earwood et al., 2020). L. mactans antivenom is usually administered to the high-risk patient with severe latrodectism (Goddard et al., 2008).

\section{CONCLUSION}

The presented cases highlight L. geometricus as a spider species of medical significance in Malaysia. This report suggests the need for better public and healthcare professionals' awareness of the existence of brown widow spider in Malaysia, the potential effects of its bite and envenomation, and the optimal clinical management. Species identification via morphological features alone can be confusing to an untrained individual. However, the identification can be verified with the DNA barcoding technique. A good transdisciplinary collaborative efforts and networking is therefore encouraged and should be supported.

\section{Declaration of Competing Interest}

The authors declare that they have no conflict of interest. 


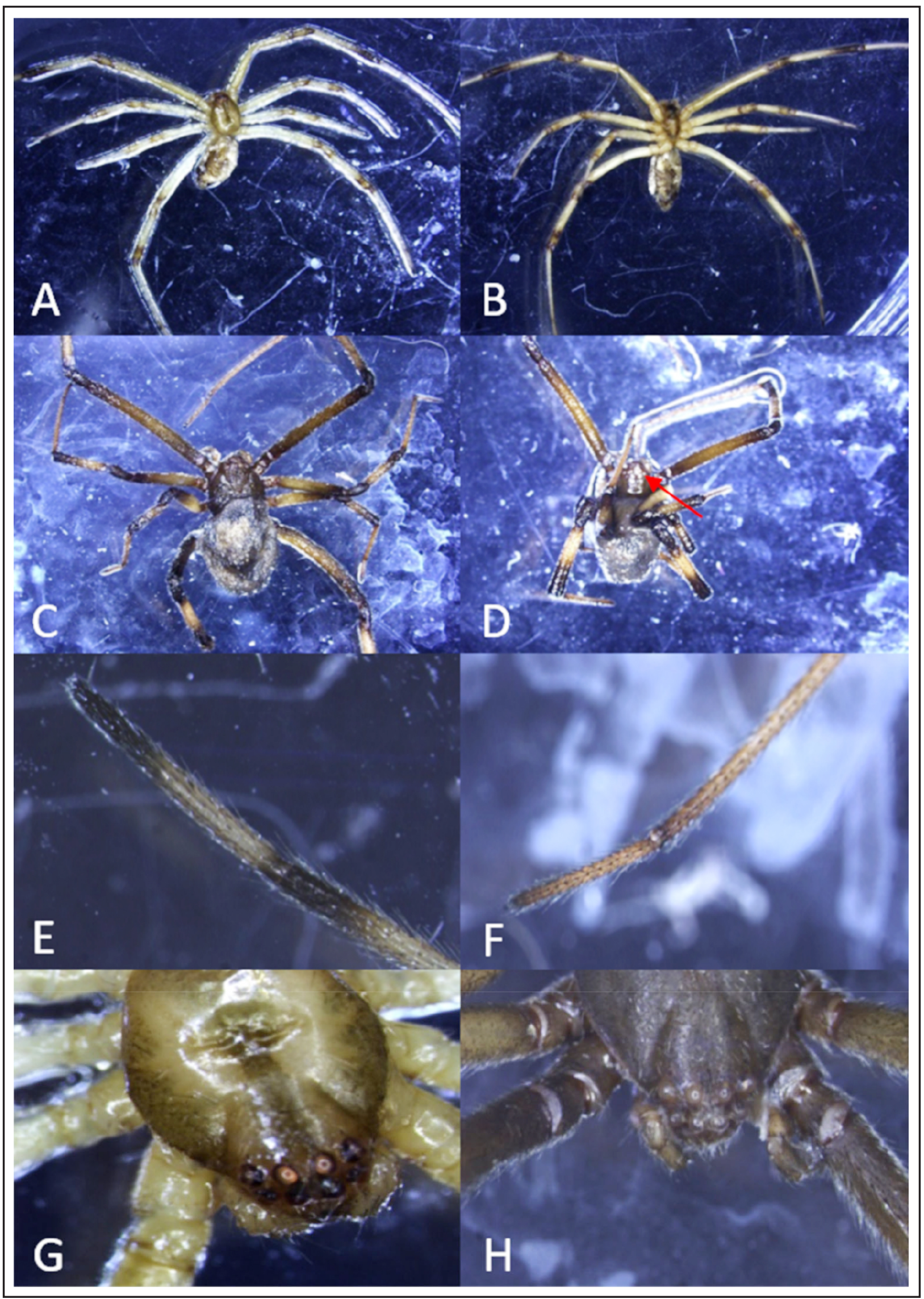

Figure 2. Morphological characteristics of Latrodectus geometricus from case reports 1 ( $A, B$, and $C)$ and 2 (D, E and F). Dorsal $(A, C)$ and ventral $(B, D)$ images of $L$. geometricus presented with light brown-coloured legs and a darker brown band on the patella, tip of tibia, metatarsus and end of tarsus, respectively. (D) The hourglass-shaped streak is clearly seen on the underside of the abdomen (red arrow). (E, F) The comb-like bristles feature of L. geometricus. (G, $\mathrm{H})$ The eye arrangement further confirms the identity of the spider. The eyes are arranged in two rows located at the distal end of the cephalothorax. 


\section{L. geometricus Sightings in Malaysia}

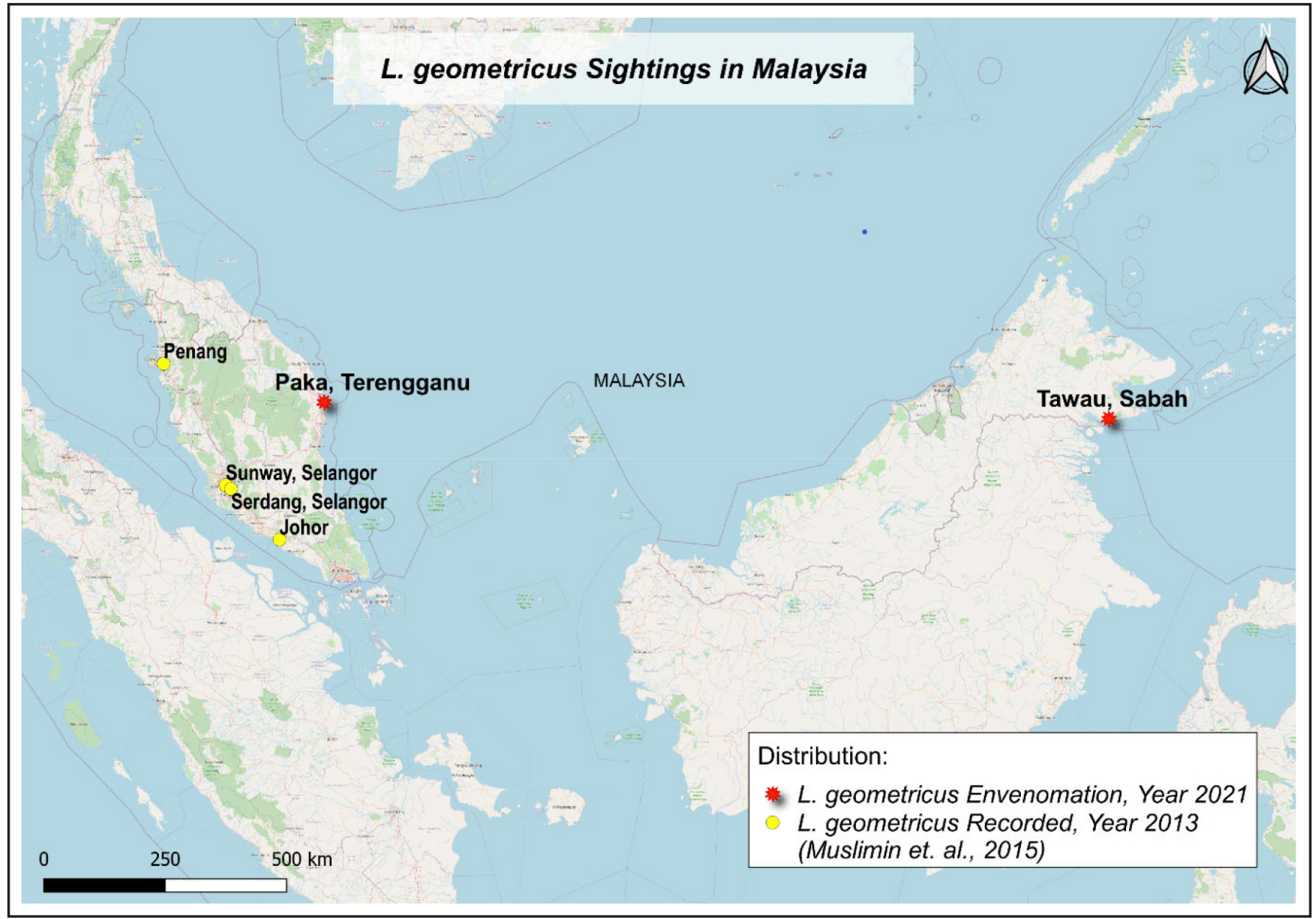

Figure 3. Distribution on reported sightings of Latrodectus geometricus in Malaysia. Map shows the distribution of L. geometricus envenomation locations in eastern of Peninsular Malaysia and northern part of Borneo (East Malaysia); marked by red dots. Previous reported sightings of $L$. geometricus (Muslimin et al., 2015) were noted in the northwest, central and south of Peninsular Malaysia; marked by yellow dots. 


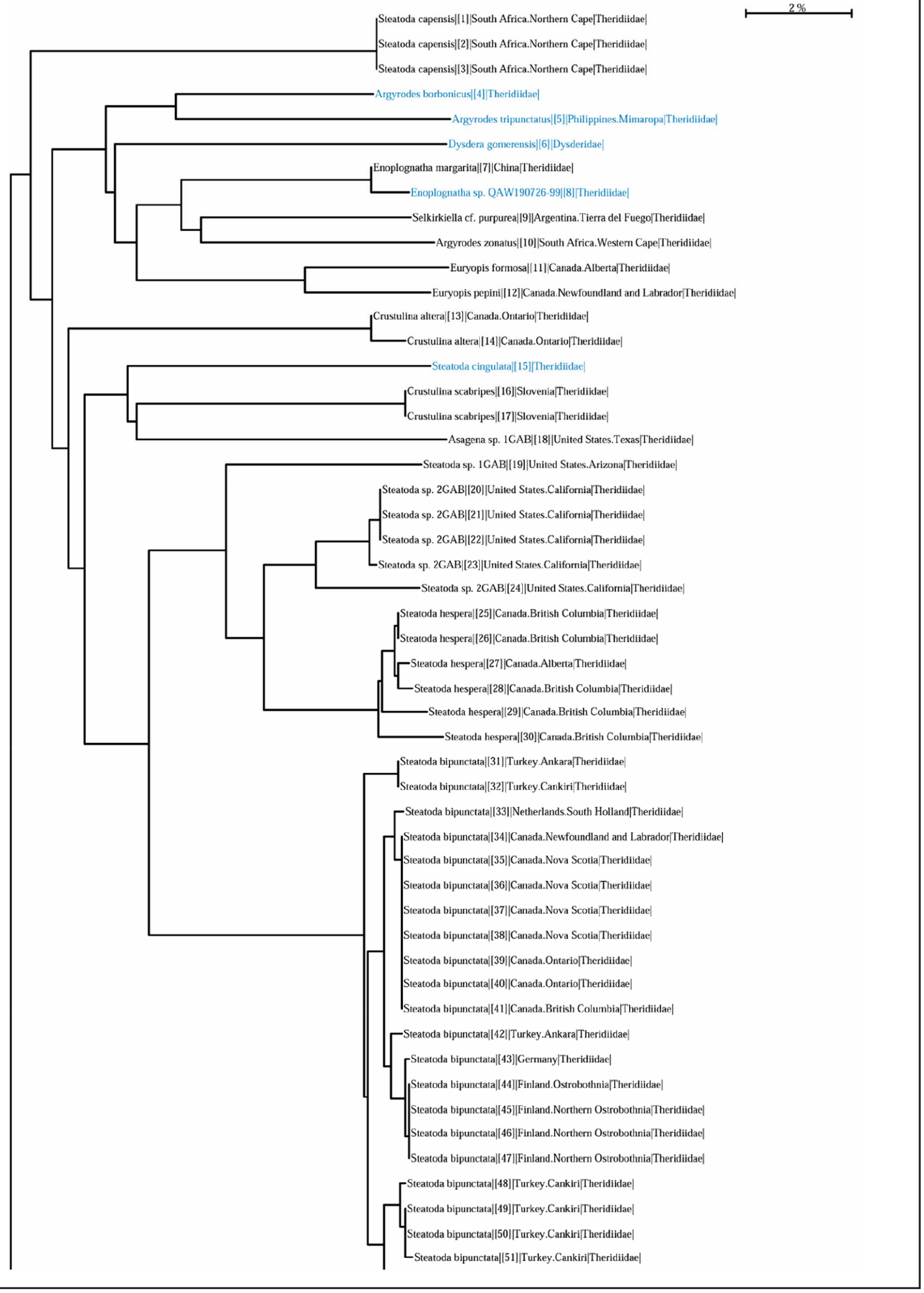

Figure 4. BOLD identification tree of offending spider from Tawau, Sabah. This tree is produced by a full database sequence identification request in BOLD. The query sequence (designated as unknown specimen) groups closely with those from United States, Dominican Republic, and Malaysia, and the species is nested within a cluster of Latrodectus geometricus. 


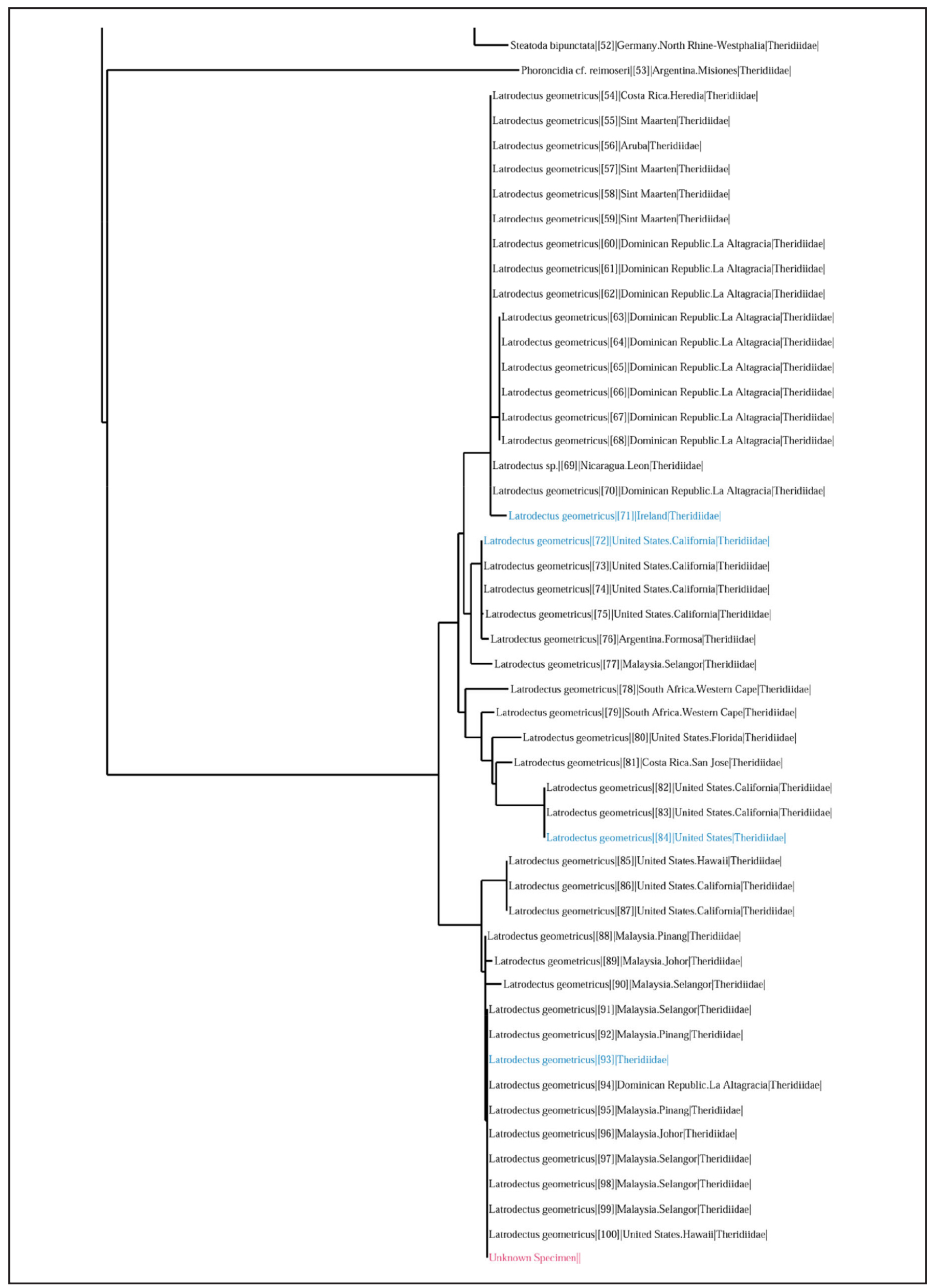

Figure 4. (continued). 


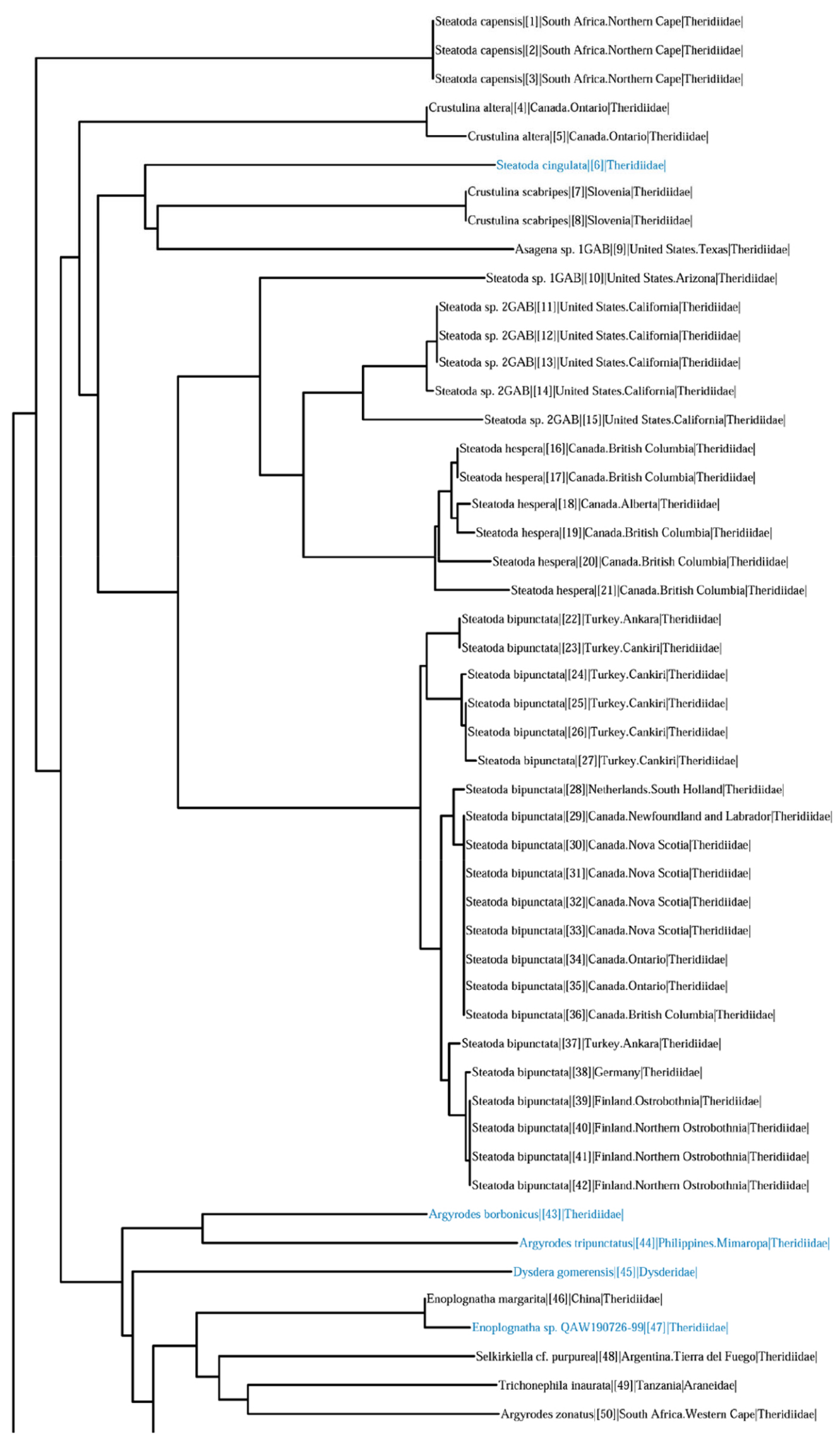

Figure 5. BOLD identification tree of offending spider from Paka, Terengganu. This tree is produced by a full database sequence identification request in BOLD. Similar to the spider in Case Report 1, the query sequence (designated as unknown specimen) groups closely with those from United States, Dominican Republic, and Malaysia, and the species is nested within a cluster of Latrodectus geometricus. 


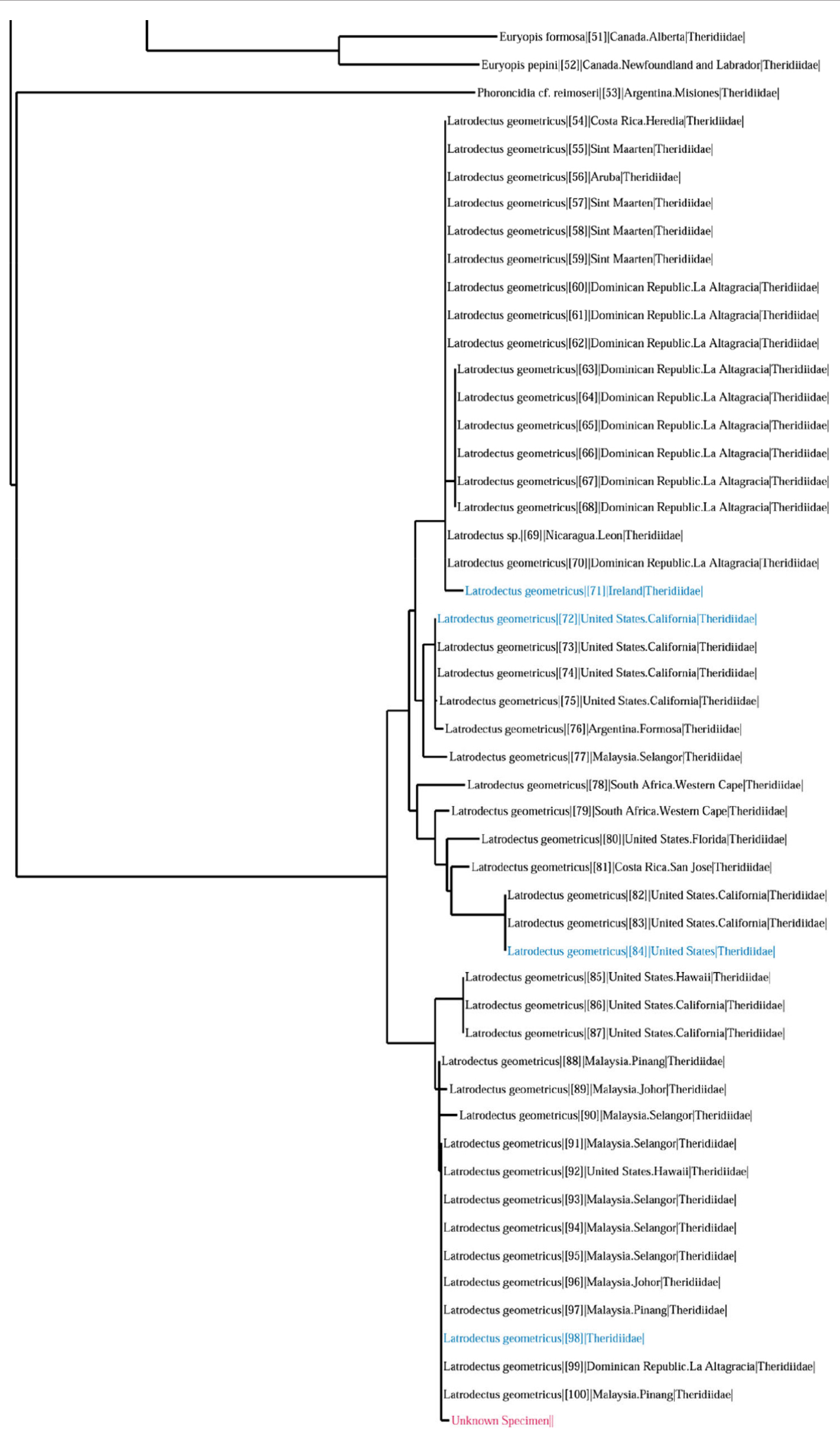

Figure 5. (continued). 


\section{REFERENCES}

Almeida, R., Ferreira Junior, R., Chaves, C. \& Barraviera, B. (2009). Envenomation caused by Latrodectus geometricus in São Paulo state, Brazil: a case report. Journal of Venomous Animals and Toxins Including Tropical Diseases 15: 562-571. https://doi.org/10.1590/S1678-91992009000300016

Cardoso, J.L.C., Brescovit, A.D. \& Haddad Jr, V. (2003). Clinical aspects of human envenoming caused by Latrodectus geometricus (Theridiidae). São Paulo Journal of Venomous Animals and Toxins including Tropical Diseases 9: 418.

de Luna, M., Rodríguez, M. \& Barrios, R.G. (2020). Predation on the common house gecko Hemidactylus frenatus Schlegel, 1836 by the brown widow spider Latrodectus geometricus Koch, 1941 in Colima, Mexico. Herpetology Notes 13: 555556.

Earwood, R.C., Ladde, J. \& Giordano, P.A. (2020). A case of brown widow envenomation in Central Florida. Cureus 12: e9165. https://doi.org/10.7759/cureus.9165

Garb, J.E. \& Hayashi, C.Y. (2013). Molecular evolution of $\alpha$ Latrotoxin, the exceptionally potent vertebrate neurotoxin in black widow spider venom. Molecular Biology and Evolution 30: 999-1014. https://doi.org/10.1093/molbev/ mst011

Goddard, J., Upshaw, S., Held, D. \& Johnnson, K. (2008). Severe reaction from envenomation by the Brown Widow Spider, Latrodectus geometricus (Araneae: Theridiidae). Southern Medical Journal 101: 1269-1270. https://doi.org/10.1097/ smj.0b013e31817f4d89

Jiménez, M.L. (1998). Aracnofauna asociada a las viviendas de la ciudad de la Paz, B.C.S., Mexico. Folia Entomológica Mexicana 102: 1-10.

Keyler, D., Ahmad, M., Rodriguez, A. \& De Silva, P. (2020). Latrodectus geometricus (Aranea: Theridiidae) envenoming: Rapid resolution of symptoms following $F\left(a b^{\prime}\right)_{2}$ antivenom therapy. Toxicon 188: 76-79. https://doi.org/10.1016/ j.toxicon.2020.10.009

Khamtorn, P., Rungsa, P., Jangpromma, N., Klaynongsruang, S., Daduang, J., Tessiri, T. \& Daduang, S. (2020). Partial proteomic analysis of brown widow spider (Latrodectus geometricus) venom to determine the biological activities. Toxicon: $X$ 8: 100062. https://doi.org/10.1016/ j.toxcx.2020.100062

Koh, J.K. \& Leong, T.M. (2013). Biodiversity in the heart of Borneo: Spiders of Brunei Darussalam. Natural History Publications (Borneo).

Lacaze, B., Dudek, J. \& Picard, J. (2018). GRASS GIS Software with QGIS. QGIS and Generic Tools 1: 67-106. https://doi.org/ 10.1002/9781119457091.ch3
McCrone, J.D. (1964). Comparative lethality of several Latrodectus venoms. Toxicon 2: 201-203. https://doi.org/ 10.1016/0041-0101(64)90023-6

Mullen, G.R. \& Durden, L.A. (2002). Medical and Veterinary Entomology, Mullen, G.R. \& Durden, L.A. (editors) 1st edition. Academic Press.

Muslimin, M., Wilson, J.J., Ghazali, A.R.M., Braima, K.A., Jeffery, J., Wan-Nor, F., Alaa-Eldin, M.E., Mohd-Zin, S.W., WanYusoff, W.S., Norma-Rashid, Y. et al. (2015). First report of brown widow spider sightings in Peninsular Malaysia and notes on its global distribution. Journal of Venomous Animals and Toxins Including Tropical Diseases 21: 1-8. https:/ /doi.org/10.1186/s40409-015-0010-2

Ratnasingham, S. \& Hebert, P.D.N. (2007). BOLD: The barcode of life data system (http://www.barcodinglife.org). Molecular Ecology Notes 7: 355-364. https://doi.org/10.1111/ j.1471-8286.2007.01678.x

Ratnasingham, S. \& Hebert, P.D.N. (2013). A DNA-based registry for all animal species: The barcode index number (BIN) system. PLOS ONE 8: e66213. https://doi.org/10.1371/ journal.pone.0066213

Rocha, C.R., Motta, P.C., Portella, A.S., Saboya, M. \& Brandão, R. (2017). Predation of the snake Tantilla melanocephala (Squamata: Colubridae) by the spider Latrodectus geometricus (Araneae: Theridiidae) in Central Brazil. Herpetology Notes 10: 647-650.

Taucare-Ríos, A., Bizama, G. \& Bustamante, R.O. (2016). Using global and regional species distribution models (SDM) to infer the invasive stage of Latrodectus geometricus (Araneae: Theridiidae) in the Americas. Environmental Entomology 45: 1379-1385. https://doi.org/10.1093/ee/ nvw118

Vetter, R.S. \& Isbister, G.K. (2008). Medical Aspects of Spider Bites. Annual Review of Entomology 53: 409-429. https:// doi.org/10.1146/annurev.ento.53.103106.093503

Vetter, R.S. (2008). Spiders of the genus Loxosceles (Araneae, Sicariidae): a review of biological, medical and physiological aspects regarding envenomations. The Journal of Arachnology 36: 150-163. https://doi.org/10.1636/RSt08-06.1

Wilson, J.J. (2012). DNA barcoding for Insects. In: Methods in Molecular Biology, Kress, W. \& Erickson, D. (editors). Totowa: Humana Press, pp. 17-46. https://doi.org/10.1007/ 978-1-61779-591-6_3

World Spider Catalog (2021). NMBE - World Spider Catalog. https://wsc.nmbe.ch 